\title{
PERJUICIO PATRIMONIAL E IMPUTACIÓN OBJETIVA
}

["Financial loss and Objective Imputation"]

\author{
Luis Emilio Rojas A.* \\ Universidad Alberto Hurtado, Chile
}

\begin{abstract}
RESUMEN
Existe poca reflexión sobre las relaciones entre la parte general y la parte especial del Derecho penal. Esto queda en evidencia cuando se revisa el intento por aplicar una categoría de la parte general, como es la imputación objetiva, a tipos de la parte especial que contemplan delitos patrimoniales, en especial la estafa. Falta una reflexión metodológica previa que explicite y ponga en cuestión las premisas de la que parte este planteamiento dogmático. El presente trabajo aborda esta discusión, concentrando su atención en el nexo entre el perjuicio patrimonial, elemento típico característico de estos delitos, y los criterios de imputación objetiva.

\section{Palabras clave}

Imputación objetiva - Delitos patrimoniales - Estafa - Perjuicio patrimonial.
\end{abstract}

\begin{abstract}
Relationships between the general and the especial aspects of the Criminal Law have not been thoroughly analyzed. This is evidenced when revising the attempt at applying a category of the general aspect, such as the objective imputation, to types of the special aspect that include financial crimes, especially fraud. There is no previous methodological reflection explicitly stating and questioning the premises from which this dogmatic statement arises. This article addresses the aforementioned discussion by focusing on the relationship between financial loss, typical feature constituting these crimes, and on the criteria of objective imputation.
\end{abstract}

\section{KEYWORDS}

Objective imputation - Financial crimes - Fraud - Financial loss.

[RECIBIDO el 14 de noviembre y ACEPTADO el 9 de diciembre de 2011].

${ }^{*}$ Doctor en Derecho por la Universidad de Friburgo en Brisgovia, profesor de Derecho penal en la Universidad Alberto Hurtado. Dirección postal: Facultad de Derecho, Universidad Alberto Hurtado, Cienfuegos 41, Santiago, Chile. Correo electrónico: lurojas@uahurtado.cl 


\section{INTRODUCCIÓN}

Una de las críticas de Armin Kaufmann en contra de la teoría de la imputación objetiva radicaba en sostener que varios de los problemas que pretendían resolverse en esa sede, en realidad, eran cuestiones que podían solucionarse con la determinación del concepto de resultado en cada tipo penal $^{1}$. De esta manera, Kaufmann pretendía mostrar que esa teoría era prescindible en la parte general del Derecho penal, en tanto planteaba problemas que podían resolverse en la parte especial ${ }^{2}$. En algunos planteamientos actuales de la dogmática penal de orientación funcionalista se tiende a seguir el camino inverso, esto es, a recurrir a criterios de imputación objetiva para resolver problemas de la parte especial del Derecho penal. Así ocurre, por ejemplo, en la dogmática moderna de los delitos patrimoniales, donde se pretende redefinir y reformular elementos típicos de estos delitos a la luz de la teoría de la imputación objetiva ${ }^{3}$. Esta tendencia es sostenible sólo si se recurre a una versión reformulada de la imputación objetiva, concebida como una teoría de la conducta injusta ${ }^{4}$. En cambio, resulta inadecuada si

\footnotetext{
${ }^{1}$ Kaufmann, Armin, ¿Atribución objetiva en el delito doloso?, en Anuario de Derecho penaly Ciencias Penales (1985), pp. 810 ss., en relación con el criterio de la dis minución del riesgo.

${ }^{2}$ Ibíd., p. 823, respecto del criterio del riesgo permitido, este sería un problema de "adecuación social" que depende de la interpretación de los tipos particulares: "[...] nos encontramos dentro de la Parte especial”; concluye, sosteniendo que sólo la causalidad y la desviación irrelevante del proceso causal representado son problemas pertenecientes a la parte general; "todos los demás problemas y casos", es decir, los discutidos bajo el concepto de "imputatio obiectiva", "pertenecen a la parte especial". Esta crítica se inserta en el cuestionamiento del status de teoría de la imputación objetiva como categoría de la parte general.

${ }^{3}$ En relación con la estafa, ya Gómez Benítez, José Manuel, Función y contenido del error en el tipo de estafa, en Anuario de Derecho penal y Ciencias Penales (1985), pp. 338 ss.; en general, respecto de la aplicación de criterios de imputación objetiva en la estafa: Pérez Manzano, Mercedes, Die objektive ZurechnungbeimBetrug, en SCHÜNEMANn - SuÁrez, Bausteine des europäischen Wirtschaftsstrafrechts. Symposiumfür Klaus Tiedemann (Köln, 1994), pp. 217 ss.; RengIER, Rudolf Gedankenzur Problematik der objektiven Zurechnungim. BesonderenTeil des Strafrechts, en Festschriftfür Claus Roxin (Berlin - New York, 2001), pp. 819 ss.; PIÑA, Juan Ignacio, Fraude de seguros (2a Edición, Editorial Jurídica, Santiago, 2006), pp. 48 ss.; recientemente, GAEDE, Karsten, Die objektive Täuschungseignungals Ausprägung der objektiven Zurechnung beim Betrug, en Festschriftfür Claus Roxin zum 80 Geburtstag (Berlin - New York, 2011), II, pp. 980 ss.; en relación a la administración desleal: SALIGER, Frank, Rechtsprobleme des Untreuetatbestandes, en Juristische Ibid., Arbeitsblätter (2007), pp. 332 ss.

${ }^{4}$ FrIsCH, Wolfgang, Comportamiento típico e imputación de resultado (Madrid, Marcial Pons, 2004), pp. 37 ss., FrIsch, Wolfgang, Faszinierendes, Berechtigtes und Problematisches der Lehre von der objektiven Zurechnung des Erfolgs, en Festschrift für
} 
se pretende aplicar simplemente esta teoría en su formulación tradicional e imperante como juicio sobre la imputación de resultado, complementario a la verificación de la causalidad5.

La discusión sobre la aplicación de criterios de imputación objetiva en los delitos patrimoniales es manifestación de las aún insuficientemente elaboradas relaciones entre la parte general y la parte especial del Derecho penal. De ahí su relevancia teórica. Sin embargo, esta discusión no se agota en su dimensión teórica. La opción por una u otra perspectiva puede tener consecuencias relevantes en la forma en que se aplican los tipos penales de los delitos patrimoniales, en especial, el tipo penal de estafa (artículo 468 CP.). El apoyo entusiasta y acrítico a la aplicación de criterios de imputación objetiva en esta clase de delitos, puede abrir la puerta para una aplicación arbitraria de los tipos penales o, eventualmente, entrar en tensión con el principio de legalidad.

A continuación, se aborda esta discusión en lo relativo al nexo entre perjuicio patrimonial (II) e imputación objetiva (III).

\section{TEORÍA DEL PERJUICIO PATRIMONIAL}

\section{Concepto de perjuicio derivado de la teoría del patrimonio.}

El concepto de perjuicio patrimonial deriva de la teoría del patrimonio. Es decir, lo que se entiende por perjuicio patrimonial depende del concepto de patrimonio que se siga. Al respecto, es posible distinguir básicamente tres teorías: la clásica o concepto jurídico, la económica y el concepto económicojurídico. La teoría clásica define el patrimonio como la suma de los derechos y deberes patrimoniales de una persona ${ }^{6}$. En consecuencia, para esta teoría el perjuicio patrimonial radica en la pérdida de un derecho o la constitución de una obligación 7 . En este sentido, Binding argumenta: "así como el Derecho penal no conoce más derecho de propiedad ni más derecho de crédito que aquel reconocido por el Derecho civil o el Derecho público, entonces también en relación con el ataque perjudicial a esos derechos es comple-

Claus Roxin (2001), pp. 231 ss.; JАковs, Günther, Objektive Zurechnung bei mittelbarer Täterschaft durch einvorsatzloses Werkzeug, en Goltdammer's Archiv für Strafrecht (1997), pp. 553 ss.: la teoría de la imputación objetiva define las reglas conforme a las cuales se determina "la forma de la conducta imputable, el sentido de la conducta [...] no la imputación de resultado".

${ }^{5}$ Roxin, Claus, Strafrecht (4a edición, München, 2006), I, $\$ 11$ núm. 53 ss.; sobre el desarrollo del concepto: Rojas, Luis Emilio Lo subjetivo en el juicio de imputación objetiva: ¿aporía teórica? en Revista de Derecho, 22 (Valdivia, 2010) 1, pp. 235 ss.

${ }^{6}$ BInDIng, Karl, Lehrbuch des gemeinen deutschen Strafrechts. Besonderer Teil (2a edición, Leipzig, 1904), I, p. 238.

${ }^{7}$ HeFEndeHL, Roland,Vermögensgefährdung und Expektanzen (Berlin, 1994), p. 93. 
tamente dependiente del Derecho patrimonial"8. De esta concepción del patrimonio y del perjuicio se sigue consecuentemente el aserto: "donde no hay derecho, no hay estafa"'. El perjuicio patrimonial pasa necesariamente por la lesión de un derecho, que no deja de existir por la mera circunstancia de que se produzca un aumento o ganancia correlativa en otra posición del patrimonio. Esto implica que una eventual compensación no es relevante en la determinación del perjuicio, éste no se puede medir según "el monstruo del valor conjunto", exclama Binding ${ }^{10}$.

Frente a este concepto, el Tribunal Supremo del Imperio alemán (Reichsgericht: RG) define el patrimonio en una sentencia plenaria del año 1887 de la siguiente forma: "Patrimonio en sentido jurídico es el conjunto de las relaciones jurídico-patrimoniales de una persona, tanto de las activas como de laspasivas, pensadas como una totalidad. Esta totalidad puede ser dañada sólo en tanto su valor conjunto en dinero disminuye, asicomo puede verse incrementada sólo en la medida en que su valor conjunto en dinero aumenta [...]". En consecuencia, el daño patrimonial en el sentido del $\$ 263 \mathrm{StGB}$. (Código penal alemán: tipo penal de estafa-), debe ser definido como "la diferencia perjudicial para el engañado entre el valor monetario que efectivamente tenia el patrimonio antes y después de la disposición provocada por el engaño y el valor monetario que habría tenido si no se hubiese realizado la acción engañosa" ${ }^{\prime 1}$. En este fallo, junto con acuñar por primera vez un concepto eco nómico de patrimonio, el RG define el método de comparación para la determinación del perjuicio. Posteriormente, el mismo Tribunal supremo radicaliza esta perspectiva en una decisión plenaria de 1910: "El concepto de patrimonio es en primera línea un concepto de la vida económica. Patrimonio es poder económico, es todo aquello que tiene valor para las relaciones económicas de una persona, es el conjunto de los valores, o, puesto que en el sistema de la economía monetaria cada valor puede expresarse en dinero: la sum a de los bienes con valor monetario de una person ${ }^{\prime \prime 2}$. A partir de este concepto, rige para

\footnotetext{
${ }^{8}$ BINDING, Karl, Eine Revolution in der Rechtsprechung des Reichsgerichts über den Betrug, en Deutsche Juristen-Zeitung (1911), p. 562

${ }^{9}$ Binding, K., Lebrbuch, cit. (n. 6), p. 343

${ }^{10}$ Ibíd., p. 358

${ }^{11}$ Reichsgericht-Strafsachen (RGSt.) 16, p. 3.

${ }^{12} R G S t$., 44, p. 233; el caso sometido a juicio trataba de un sujeto que ofrecía un medio abortivo por un precio de 10 marcos a mujeres embarazadas, las que efectivamente lo compraron y usaron, resultando ser dicho medio en realidad un polvo inocuo, cuyo precio no superaba los 30 a 40 peniques; el Tribunal de instancia (Landgericht) lo condena a título de estafa, consciente de que se apartaba de la jurisprudencia del Reichsgericht que hasta entonces se inclinaba por un concepto jurídico de patrimonio (en RGSt., 44, p. 231); el pleno del Tribunal supremo comienza el fallo señalando que existe acuerdo en el sentido que el concepto del patrimonio jurídicamente protegido
} 
la determinación del perjuicio patrimonial el principio general que "en tanto un y el mismo suceso ha traído al mismo tiempo perjuicio y ganancia, ambos deben ser ponderados uno contra el otro, de tal manera que solamente existe daño en tanto queda al superar el perjuicio a la ventaja patrimonial"'3. Para este concepto de perjuicio, lo determinante no es la lesión de un derecho, sino la disminución del valor económico del patrimonio. De ahí que en este concepto se admita la posibilidad de la compensación, ya que si el valor monetario de la disminución patrimonial equivale al valor de una ventaja conectada inmediatamente a la disposición, entonces no existe un saldo negativo $y$, por tanto, no hay perjuicio ${ }^{14}$.

Este concepto parece estar situado en las antípodas del concepto jurídico. Sin embargo, Gallas ha puesto de manifiesto que tal oposición es exagerada, pues ninguno de los dos conceptos puede sostenerse en términos puros ${ }^{15}$. La teoría clásica al usar el concepto de de recho pat ri monial en la definición de patrimonio, está incluyendo en el contenido del concepto aquello que pretende definir. Para no moverse en círculo, este concepto debe recurrir a un parámetro económico, exigiendo que el derecho sea portador en general y abstracto de valor económico, no necesariamente en concreto, en el sentido de ser objeto actual de transacción. Por su parte, tampoco el concepto económico puede prescindir de la dimensión jurídica: "el concepto de patrimonio, también en su acepción económica, no pertenece a un mundo amoral de meras relaciones de poder, sino a una realidad social por principio referida a valores de ordenamiento; presupone una tenencia legítima asegurada

es equívoco, pues provoca la impresión de que existe patrimonio que jurídicamente no es protegido, "y eso sería una contradicción en si misma, pues aquello que pertenece al patrimonio de una persona y que es parte de su patrimonio goza bajo toda circunstancia de protección jurídica".

${ }^{13}$ RGSt., 44, p. 237; este fallo es sometido a una fuerte crítica de BINDING, Karl, en DJZ. cit. (n. 8), pp. 558 y ss.: el patrimonio puede ser valorado en dinero, pero siempre en un momento determinado; el mismo patrimonio con los mismos derechos y deberes puede tener los más distintos valores monetarios, por ej. títulos de valor que hoy no valen nada, pueden alcanzar un alto valor en diez años; respecto del caso, niega ya la concurrencia de un error relevante: "quien paga dinero para obtener un medio abortivo, sabe exactamente que no es lícito recibirlo, por lo tanto, si no lo recibe, entonces no puede ser engañado, pues no existe una cuenta jurídicamente relevante por la realización de una acción prohibida”; la ilicitud de la contraprestación era clara para las compradoras, sólo una esperanza de recibir contra Derecho la contraprestación se ha visto frustrada, "se trata de una autolesión no responsable, para la cual el Derecho con buen fundamento niega su intervención".

${ }^{14}$ Nelles, Ursula, Untreue zum Nachteil von Gesellschaften (Berlin, Duncker \& Humblot, 1991), p. 343.

${ }^{15}$ Gallas, Wilhelm, Der Betrug als Vermögensdelikt, en Bockelmann, Paul - GaLLAS, Wilhelm (editores), Festschrift für Eberhard Schmidt (Göttingen, 1961), p. 407. 
frente a ataques de terceros, un poder-disponer intacto en todo momento. Por tanto, patrimonio es pensable sólo en el marco y bajo la protección del Derecho" ${ }^{16}$. De esta manera, Gallas destaca el carácter necesariamente accesorio del Derecho penal patrimonial: "El Derecho penal puede por cierto determinar en qué medida pretende proteger el patrimonio; no puede sin embargo emanciparse de las normas determinantes de la asignación jurídica de bienes y por ejemplo volver, en contra de las reglas del Derecho privado, una posibilidad fáctica de ganancia basada en un negocio jurídico ilícito en una parte del patrimonio y con ello en un bien disponible en el marco del Derecho" ${ }^{17}$. Porque el concepto jurídico de patrimonio no puede prescindir completamente de un parámetro económico para concretar el derecho como elemento constituyente y porque el concepto económico presupone el marco del ordenamiento jurídico para no incurrir en contradicciones valorativas insalvables ${ }^{18}$. Por eso la teoría dominante en la dogmática de los delitos patrimoniales suscribe un concepto económicojurídico, que alcanza una formulación sintética, nuevamente, en un fallo del Tribunal Supremo del Reino alemán de 1932: "el concepto de patrimonio en el sentido del \$263 StGB va más allá de los derechos jurídico-privados (de bienes o créditos) adquiridos. Significa el conjunto de los valores económicos cuya disposición se encuentra permitida a una persona bajo protección del ordenamiento jurídico [...]. Al patrimonio pertenecen todos los intereses económicos de una persona que pueden ser realizados bajo la protección del ordenamiento jurídico o en un proceso regulado" 1 .

\section{Principios de la determinación del perjuicio.}

Este concepto económico-jurídico de patrimonio, del mismo modo que el económico puro, llevan a un concepto eco nó mico de perjuicio ${ }^{20}$. Según este concepto, existe perjuicio en la medida en que el patrimonio de la víctima sufre una merma económica como consecuencia de la conducta del autor.

${ }^{16}$ Ibíd., p. 408.

${ }^{17}$ Ibíd., p. 408.

${ }^{18}$ Nelles, U., cit. (n. 14), pp. 384 ss., ha criticado la premisa de la que parte la teoría dominante, que limita o corrige desde fuera el concepto económico; recurriendo a la teoría de sistemas, sostiene que no hay relación de contradicción, sino que derecho y economía son subsistemas del sistema social con sus propios códigos de operación.

${ }^{19}$ RGSt., 66 (281), p. 284 s.; no obstante, es preciso aclarar que Gallas, W., cit. (n. 15), pp. 407 s., 409, 417, no sostiene un concepto económico-jurídico de patrimonio en la acepción de la teoría dominante, sino que suscribe más bien un concepto jurídico corregido económicamente, esto es, un concepto jurídico-económico: conjunto de los derechos patrimoniales con valor monetario (abstracto) de una persona,

${ }^{20}$ Joecks - Miebach (editores), Münchener Kommentar zum Strafgesetzbuch (München, 2006), IV, núm. 444. 
Resulta entonces decisivo fijar el baremo y el procedimiento para constatar si la víctima efectivamente ha sufrido tal pérdida patrimonial. En cuanto al baremo, es importante tener presente que cuando se habla de merma económica no se alude a cualquier criterio de valoración extraído de la ciencia económica. Se trata de un parámetro determinado de valoración, cual es el valor monetario. Según el concepto económico de perjuicio, el baremo que permite determinar si el patrimonio de la víctima ha sufrido efectivamente una merma, es el valor monetario del $\mathrm{mismo}^{21}$. Junto con determinar el parámetro de valoración, se fija el momento en que se compara el valor del patrimonio, esto es, en la estafa, con la disposición de la víctima ${ }^{22}$. Es decir, se compara el valor monetario del patrimonio antes con el valor del mismo después de la disposición, de tal modo que si éste es inferior al primero, hay perjuicio patrimonial. Este procedimiento de comparación se denomina principio del saldo, el cual debe ser negativo para estar en presencia de perjuicio. Si es igual a cero o incluso positivo, entonces conceptualmente no hay perjuicio. Este principio, a su vez, conduce a la aceptación de la com pensación, es decir, a la posibilidad de que la disminución del valor producida por la disposición de la víctima se vea compensada por un incremento patrimonial vinculado a la misma disposición. Esta posibilidad de compensación plantea, sin embargo, la pregunta por los límites, esto es, por la clase de incrementos patrimoniales vinculados a la disposición susceptible de ser considerada. Al respecto, rige un criterio de in mediatez, que permite excluir del procedimiento de compensación aquellos cambios temporalmente posteriores a la disposición, por ejemplo, variaciones en el valor de acciones adquiridas ${ }^{23}$. Por otra parte, no es posible valorar en este procedimiento las pretensiones jurídicas de indemnización de la víctima nacidas del hecho mismo constitutivo de delito ${ }^{24}$. Pero sí es posible considerar otras pretensiones jurídico-civiles de la víctima, en tanto no tengan su fundamento en el hecho mismo, lo que ocurre, por ejemplo, con las garantías suficientes y realizables por la víctima sin intervención del autor o de terceros ${ }^{25}$.

\footnotetext{
${ }^{21}$ Laufhütte - Rissing - van SaAn - Tiedemann (editores), Strafgesetzbuch Leipziger Kommentar (11 a edición, Berlin, 1999), IX, núm. 158 ss.

${ }^{22}$ Ibíd., núm. 160.

${ }^{23}$ Ibíd., núm. 162.

${ }^{24}$ Ibíd., núm. 166.

${ }^{25}$ Ibíd., núm. 167.
} 


\section{Peligro patrimonial equivalente al daño.}

Una forma límite del perjuicio, que permite colocar a prueba el rendimiento del concepto económico, es el peligro para el patrimonio equivalente al daño. Se trata de un grupo de casos en que el patrimonio de la víctima es colocado en una situación de incerteza existencial ${ }^{26}$, sin que se produzca aún una merma o pérdida patrimonial efectiva, pero en que ya ese estado puede implicar una disminución del valor económico. Ejemplos: mediante engaño, el autor logra que la víctima le entregue un título de crédito firmado en blanco, anote una deuda inexistente en su registro de contabilidad o autorice el otorgamiento de un préstamo, sin esperar, respectivamente, que el autor o un tercero cobre efectivamente el crédito o no pague la deuda. Existe la posibilidad de fundamentar un perjuicio en estos casos, a pesar de no existir aún una pérdida sustancial, justamente desde la perspectiva del concepto económico. Como explica Hefendehl: "pues, sea como sea que se defina el concepto de lo económico, lo claro es en todo caso que en la vida económica se desvalora no solamente la pérdida efectiva sustancial"27. Esto significa que, desde esa perspectiva, ya la situación de peligro puede implicar una disminución de valor del patrimonio, aun cuando no se constate una pérdida efectiva.

La pregunta que surge respecto de esta figura dice relación con el momento y los criterios según los cuales es posible determinar la configuración perjudicial del peligro patrimonial. Pues, existe consenso en que la mera situación de peligro no es suficiente para la configuración del perjuicio. La mera circunstancia, por ejemplo, que el autor o un tercero ya obtenga la tenencia material del título de crédito o que la propia víctima haya anotado un crédito en su favor en el registro contable, no implica de por sí fundamentación del perjuicio. Debe tratarse de un peligro patrimonial equivalente al daño, esto es, la situación de peligro debe haberse desarrollado de tal manera que ya no sea posible hacer una distinción cualitativa con la configuración del perjuicio. En este sentido, se exige que se trate de un peligro con cre to para el patrimonio. Sin embargo, la concreción del peligro es determinable según un criterio cuantitativo, cuya aplicación obliga a fijar un rango de probabilidad, siempre difícil de determinar. De ahí que se recurra a otros criterios de delimitación, como ocurre con la invocación de los principios de la tentativa. Mediante la aplicación de estos criterios se busca evitar que por medio de esta figura del peligro patrimonial se castigue a título de consumación un hecho constitutivo de estafa que sólo ha alcanzado el grado de tentativa. Según esta solución del problema, el peligro

${ }^{26}$ La expresión "Daseinsungewissheit" proviene de Binding y es recuperada por Kindhäuser para denotar su propio concepto práctico de peligro; véase: KINDHÄUSER, Urs, GefährdungalsStraftat (Frankfurt, 1989), p. 208.

${ }^{27}$ Hefendehl, R., Vermögensgefährdung, cit. (n. 7), p. 67. 
aún concreto para el patrimonio no es equivalente al daño, en tanto pueda atribuirse al ámbito de la tentativa y el autor pueda por tanto aún desistirse del hecho. Para poder determinar si el peligro es atribuible al ámbito de la tentativa, se recurre a un criterio de in mediatez, de tal modo que, si entre el peligro y su realización efectiva es menester aún otra conducta del propio autor, de la víctima o un tercero, entonces no puede estimarse equivalente al daño y hay por tanto sólo tentativa ${ }^{28}$. La así llamada solución de la tentativa ha sido con razón criticada por Hefendehl de contradictoria, pues a pesar de encontrarse completo el tipo objetivo, se finge la no configuración del perjuicio. Lo determinante para esta pregunta es el concepto de patrimonio y sólo a partir de éste es posible aclarar si hay estafa consumada o sólo tentada. La pegunta de la tentativa está subord in ad a a la configuración del perjuicio según el concepto de patrimonio ${ }^{29}$. Asimismo, la invocación del criterio de in media tez para determinar la equivalencia del peligro al daño conduce en la estafa a la abstrusa exigencia de una doble inmediate ${ }^{30}$. Pues, ya en sede de disposición patrimonial se exige un nexo de inmediatez entre disposición y disminución patrimonial para que aquella sea típica de estafa, por lo que además exigir inmediatez entre peligro y realización del daño implica caer en una argumentación circular. El mismo criterio de inmediatez serviría para concretar la disposición patrimonial y al mimo tiempo para concretar el peligro para el patrimonio ${ }^{31}$. Para evitar incurrir en una definición tautológica -v. gr.: hay estafa sólo tentada cuando se atribuye el peligro al ámbito de la tentativa-, es preciso fijar el baremo desde el cual valorar la disposición patrimonial de la víctima. Si se sigue la teoría dominante y se suscribe un concepto económicojurídico de patrimonio que lleva a un concepto económico de perjuicio, entonces el baremo es el valor económico o monetario del bien. Esto significa, en definitiva, que en sede de perjuicio patrimonial no se constata la existencia de un elemento separado espacio-temporalmente de la disposición patrimonial, sino que más bien se valora económicamente la conducta de disposición de la víctima realizada bajo error. De este concepto fluye la siguiente conclusión: perjuicio es valoración económica negativa de la disposición patrimonial de la víctima ${ }^{32}$.

${ }^{28}$ Riemann, Thomas,Vermögensgefährdung und Vermögensschaden (Heidelberg, 1989) p. 57.

${ }^{29}$ Hefendehl, R.,Vermögensgefährdung, cit. (n. 7), p. $73 \mathrm{s.}$

${ }^{30}$ Ibíd., pp. 148ss.

${ }^{31}$ Por eso crítico también Tiedemann, K., cit. (n. 21), núm.109.

${ }^{32}$ Rojas, Luis Emilio Grundprobleme der Haushaltsuntreue. Zugleiche in Beitrag zur Dogmatik der Untreue, en StGB. 266 (Baden-Baden, 2011), pp. 212 ss., en relación al perjuicio patrimonial en la administración desleal, con la diferencia que la disposición es realizada, infracción de deber mediante, por el propio autor. 


\section{III. ¿IMPUTACIÓN OBJETIVA DEL PERJUICIO PATRIMONIAL?}

\section{Sentido del juicio de imputación objetiva.}

En casos difíciles, como por ejemplo los de peligro patrimonial, existe la tentación metodológica de recurrir a los criterios desarrollados en el marco de la teoría de la imputación objetiva para suplir los vacíos que aparentemente deja la dogmática de los delitos patrimoniales. Este camino estaría indicado por la circunstancia de que estos delitos, en tanto exigen para su atribución típica la provocación de un perjuicio patrimonial a otro, están configurados como delitos de resultado y, por tanto, a su respecto sería posible plantear preguntas de imputación objetiva de resultado. Pues bien, la invocación de la teoría de la imputación objetiva para resolver problemas de imputación en los delitos patrimoniales parte de la premisa que es metodológicamente lícito trasladar una categoría de la parte general desarrollada para normativizar tipos penales que describen básicamente un puro acontecimiento natural a un delito como la estafa, cuyos elementos típicos han estado desde siempre fuertemente normativizado ${ }^{33}$. Esta premisa metodológica desconoce el fundamento que condujo a la creación y desarrollo de la teoría de la imputación objetiva. Este concepto nació por la profunda insatisfacción que generaba la atribución penal del resultado al autor basada solamente en la causalidad, particularmente en los casos de cursos causales irregulares o atípicos, por ejemplo, en el "caso del sobrino" que envía a su tío al bosque con árboles en altura con la intención de muerte, la que efectivamente sucede producto de un rayo que cae sobre el tío en medio de una tormenta. Frente a este grupo de casos, tanto Karl Larenz desde la Filosofía del Derecho como Richard Honig

${ }^{33}$ Perez Manzano, M., cit. (n. 3), pp. 213 ss., parte de un modo bastante acrítico de esta premisa, pues invoca la calidad de delito de resultado de la estafa para sostener que no existe ninguna razón para restringir la aplicación de la teoría de la imputación objetiva sólo al grupo de delitos de resultado constituido por el homicidio y las lesiones corporales, cuando la pregunta es justamente por la existencia de una razón o fundamento para justificar la necesidad de aplicación de tales criterios a los delitos patrimoniales. Recientemente, GAEDE, Karsten, cit. (n. 3), pp. 970 ss., discute explícitamente sobre esta premisa y sostiene que en las "teorías generales de la imputación de resultado" se expresa el concepto fundamental de los delitos de resultado, que se obtiene mediante un análisis sistemático del material jurídico-penal de la parte especial y del cual se extraen exigencias generales de racionalidad de los delitos de resultado; pero, en esa medida y en atención al mandato de determinación legal consagrado en el artículo 103 párrafo 2 de la Ley Fundamental, la consideración de este concepto fundamental de los delitos de resultado debe realizarse en el marco de la interpretación de los elementos típicos, ya sea en la determinación del sentido posible de un elemento del tipo o, según la clase de delito, mediante la formulación de elementos no escritos entre elementos típicos; no obstante, no puede conducir a la simple sustitución de un elemento típico mediante un criterio de imputación objetiva. 
desde la dogmática penal vieron correctamente que el juicio de causalidad era insuficiente y que debía plantearse una pregunta epistemológicamente distinta, una pregunta teleológica o axiológica que denominaron juicio de imputación objetiva ${ }^{34}$. No se trata de un problema de causalidad, sino que de imputación objetiva. Este concepto, que posteriormente es desarrollado teórica y pormenorizadamente por Claus Roxin ${ }^{35}$ y Günther Jakobs ${ }^{36}$ en el marco del funcionalismo en Derecho penal, nace para resolver un grupo de casos que se plantea en cierta clase de delitos de resultado que exigen un nexo causal y cuya mera constatación precisamente se estima inadecuada para fundamentar la responsabilidad penal del autor por el resultado. En una frase, el juicio de imputación objetiva complementa el juicio de causalidad, pero presupone la existencia de un nexo causal entre conducta y resultado ${ }^{37}$.

Esto último, es decir, la existencia de un nexo causal resulta bastante dudosa en el delito de estafa. En primer lugar, sólo en un sentido muy amplio y en un uso un tanto forzado del lenguaje puede decirse que el engaño causa el error. En un enfoque naturalista y psicologicista de la estafa puede decirse que el engaño, en tanto que declaración falsa, causa la representación a su vez falsa que configura el error. Pero, en rigor, entre engaño y error no existe un nexo de causalidad, sino una relación de sentido, esto es, atribución de significado por parte de la víctima a la declaración falsa del autor ${ }^{38}$. Esto resulta patente en los casos de engaño concluyente, donde ni siquiera puede hablarse propiamente tal de declaración y, por tanto, donde hay pura atribución de significado a una conducta del autor ${ }^{39}$. En segundo lugar, con respecto al nexo entre error y disposición patrimonial, es derechamente abstruso sostener una relación de causalidad entre ambos momentos que suceden en un mismo sujeto. Sólo en una concepción naturalista extrema podría decirse que la representación falsa que sería el error causa "en la misma cabeza” del sujeto la disposición patrimonial que no es otra cosa que una decisión de la víctima en relación a su patrimonio. Nuevamente, la disposición patrimonial es motivada, no causada por el error.

${ }^{34}$ Rojas, L. E., Lo subjetivo, cit. (n. 5), pp. 237 ss.

${ }^{35}$ Roxin, C., Strafrecht, cit. (n. 5), \$11 núm. 44 ss.

${ }^{36}$ Jаковs, Strafrecht. Allgemeiner Teil (2a edición, Berlin - New York, 1993), apdo. 7 , núm. 35 ss.

${ }^{37}$ Roxin, C., cit. (n. 5), $\$ 11$ núm. 3 ss.

${ }^{38}$ Puppe, Ingeborg, Die Erfolgszurechnung im Strafrecht (Baden-Baden, 2000), pp. 58 ss., crítica a la "causalidad psíquica": "todo lo que hacemos, lo hacemos por razones, sean éstas técnicas o éticas".

${ }^{39}$ FRISCH, Wolfgang, Grundfragen der Täuschung und des Irrtums beim Betrug, en Festschrift für Rolf Dietrich Herzberg (Tübingen, 2008), pp. 740 ss.; EL MISMO, Konkludentes Täuschen, en Festschrift für Günther Jakobs (Köln, 2007), pp. 98 ss. 
En cuanto al nexo entre disposición y perjuicio patrimonial, tampoco puede hablarse con propiedad de una relación de causalidad. Justamente la solución de la tentativa en la discusión sobre el peligro patrimonial, parece suscribir un paradigma causalista en que el peligro es el campo previo a la producción del perjuicio, donde peligro y perjuicio son vistos como dos acontecimientos externos separados entre $s^{4}{ }^{40}$. Hefendehl ha puesto en cuestión la existencia de un nexo causal entre disposición y perjuicio como dos acontecimientos externos temporalmente secuenciales. La disposición patrimonial no tiene una función autónoma; si no existe posibilidad de compensación, entonces disposición y perjuicio coinciden en un mismo instante. De ahí que en lugar de nexo causal, se plantee un proceso con distintas perspectivas de valoración: disposición y perjuicio son dos pasos en el mismo proceso valorativo del aplicador del Derecho ${ }^{41}$.

\section{Criterios de imputación objetiva.}

Las reflexiones anteriores conducen a una aproximación más bien escéptica sobre la viabilidad de aplicación de esta teoría en los delitos patrimoniales, especialmente en la estafa. Esta teoría fue creada y desarrollada para modular las consecuencias a las que conduce la aplicación pura del criterio de causalidad. Precisamente en esta medida, presupone la existencia de un nexo causal. Si en los delitos patrimoniales ni siquiera puede hablarse lícitamente de causalidad, entonces tampoco estaría indicada la aplicación de criterios de imputación objetiva. En general, los planteamientos que pretenden tal aplicación no se detienen mayormente en el significado y fundamento de cada criterio de imputación objetiva, lo que conduce a una aplicación un tanto automática y poco reflexiva de la teoría ${ }^{42}$.

Estos criterios de imputación pueden dividirse en dos grandes grupos, por una parte, aquellos que dicen relación con la creación jurídicamente desaprobada del riesgo, como el riesgo permitido o el principio de autorresponsabildad, y, por otra, los que atañen al nexo de realización del riesgo jurídicamente reprobado, entre los que se incluyen los casos de la conducta

${ }^{40}$ Véase la crítica al concepto causalista de peligro en KINDHÄUSER, Urs, cit. (n. 26) p. 203 s., aunque enmarcada en la discusión sobre la legitimación de los delitos de peligro.

${ }^{41}$ Hefendehl, R., Vermögensgefährdung, cit. (n. 7), pp. $146 \mathrm{~s}$.

${ }^{42}$ Lo que, en algunos casos, conduce a una cierta adaptación y modificación del criterio original de imputación, por ejemplo, cuando en relación a la "idoneidad" del engaño se distingue según el "nivel intelectual” de la víctima así, Pérez Manzano, Mercedes cit. (n.33) p. 218, aspecto ajeno a la teoría de la imputación objetiva, que discute sobre la relevancia de los conocimientos y capacidades especiales del autor, Roxin, C., it. (n. 5), $\$ 11$ núm. $56 \mathrm{~s}$. 
alternativa hipotética conforme a Derecho ${ }^{43}$. En relación al primer conjunto de criterios de imputación, según el cual se determina si la creación del riesgo para el bien jurídico es jurídico-penalmente desaprobada, puede servir por ejemplo para la determinación de la conducta típica del delito de estafa. En particular, el criterio del riesgo permitido podría ser útil en este sentido. Sin embargo, si se entiende por riesgo la probabilidad de realización del resulta$\mathrm{do}^{44}$, entonces tal utilidad resulta ser sólo aparente. Porque la conducta típica del delito de estafa no está definida a partir del concepto de riesgo ${ }^{45}$. En los delitos de resultado de los tipos penales de homicidio y lesiones corporales, tiene sentido la construcción normativa de la conducta típica a partir del concepto de riesgo, pues allí siempre se trata de la probabilidad de realización del resultado descrito en el tipo. En cambio, en la estafa, la construcción de la conducta típica a partir del concepto de riesgo, tendría que esclarecer qué ocurrencia de suceso es aquella, respecto de cuya probabilidad se formula el juicio normativo de desaprobación: la ocurrencia de los elementos no escritos del error y de la disposición patrimonial o el elemento típico del perjuicio ${ }^{46}$.

${ }^{43}$ Roxin, C., cit. (n. 5), $\$ 11$ núm. 106 ss., agrega un tercer grupo discutido bajo el criterio del "alcance del tipo" que incluye, entre otros, los casos de autoexpuesto en peligro de la víctima.

${ }^{44} \mathrm{Cfr}$. sobre el concepto de riesgo, vinculado indisolublemente a probabilidades, $\mathrm{y}$ su distinción del concepto de peligro, entendido como curso causal potencialmente dañoso, desde la ética del riesgo, Nida-Rümelin, Julian, Ethik des Risikos, en Angewandte Ethik (Stuttgart, 2005), p. 4.

${ }^{45}$ En cambio, en ciertos casos de administración desleal sí puede tener sentido reinterpretar la conducta típica bajo el concepto de riesgo. Se trata de casos de administración desleal en el marco de "negocios riesgosos", esto es, casos en que el administrador somete al patrimonio ajeno a un nivel de riesgo no autorizado por el titular del patrimonio o, en caso de ausencia de instrucciones, no permitido en el sentido de exceder las máximas del "buen administrador", ej. el corredor de bolsa al cual la víctima le encarga la venta de acciones y, con el producto de ésta, la compra de otras. Pero, aún en ese grupo de casos, la invocación del criterio del "riesgo permitido" parece cumplir un rol puramente nominal, pues si hay o no un riesgo prohibido depende de si hay o no infracción del deber de cuidado patrimonial, que obliga a velar por los intereses patrimoniales de la víctima y que es presupuesto del tipo de administración desleal; al respecto, ya clásico Hillenkamp, Thomas, Risikogeschäft und Untreue, en Neue Zeitschrift für Strafrecht (1981), pp. 164 ss.: "no se trata de la pregunta de si una conducta riesgosa puede legitimarse según las valoraciones de un ordenamiento económico y social o de un empresario correcto, sino más bien si la conducta puede legitimarse frente al titular del patrimonio" en la medida que la administración busque alcanzar el objetivo en el marco de la "política de riesgo" definida por el titular, no hay administración desleal.

${ }^{46}$ Esta multiplicidad de sucesos de probable realización es la que conduce a una aplicación forzada de las categorías de la imputación objetiva, así, por ejemplo, RENGIER, R., cit. (n. 3), p. 820: "el peligro no permitido proveniente del engaño debe continuar influyendo en los resultados intermedios - del error y la disposición patrimonial 
Ya esta multiplicidad de sucesos de probable realización es indicativa que no se trata aquí de un problema de riesgo. Dicha conducta se delimita en base al concepto de engaño, que no significa otra cosa que una declaración falsa, y respecto del cual sólo cabe preguntarse cuando se está en presencia de un engaño típico de estafa ${ }^{47}$.

En cuanto al error típico, se critica su contenido "psicológico", en tanto representación falsa, y se propone sustituirlo por criterios de imputación objetiva ${ }^{48}$. En este marco, la función del error sería, en base a los criterios de "aumento del riesgo" y subsidiariamente del "fin de protección de la norma", determinar la "idoneidad" del engaño para provocar el acto de disposición perjudicial, idoneidad que faltaría cuando la víctima tuviese posibilidades "naturales o jurídicas" de autoprotección, pero que concurriría en los casos de duda en que no habría un error entendido psicológicamente ${ }^{49}$. Esta propuesta de sustitución del elemento error por criterios de imputación objetiva adolece de falta de claridad sobre el alcance de los criterios invocados, "aumento del riesgo" y "fin de protección de la norma", en la medida en que no esclarece los casos que cada criterio filtra ni cómo se comporta uno en relación al otro. Pero sobre todo parte de una imagen artificial del complejo fáctico constitutivo de estafa, en que, por un lado, el engaño se comprende como una suerte de acontecimiento causal en curso hacia la disposición patrimonial perjudicial. $\mathrm{Y}$, por otro lado, el error se redefine normativamente como una instancia de adecuación y valoración que discierne los perjuicios patrimoniales imputables objetivamente al engaño como resultado típico de los que no lo serían como tales. Por otra parte, la invocación del principio de subsidiariedad para sostener la no imputación en caso que la víctima disponga de posibilidades de autoprotección ${ }^{50}$, merece reparos. Ya Frisch, en el año 1979, había criticado la invocación de un principio general, aplicable más bien a los delitos de daño ajeno, sin adaptarlo al contexto especial de un delito "interaccional" como

- hasta ser 'transportado' (sic) al perjuicio"; GAEDE, K., cit. (n. 3), p. 98 ss., respecto de la realización del peligro, debe atenderse primeramente a los resultados "intermedios" del error y "sobre todo" de la disposición patrimonial, sobre los cuales se realiza el resultado del hecho "final" del perjuicio patrimonial. Pero, en definitiva, el riesgo prohibido derivado del engaño, ¿consiste en la probabilidad de realización de qué suceso, del resultado "final" del perjuicio patrimonial, de la disposición patrimonial "principalmente relevante" o del simple "resultado intermedio" del error?

${ }^{47}$ HeRnÁndez, Héctor, Normativización del engaño y nivel de protección de la victima en la estafa: lo que dice y no dice la dogmática, en Revista Chilena de Derecho, 37 (2010) 1, pp. 15 ss.

${ }^{48}$ Gómez Benítez, José Manuel, cit. (n. 3), pp. 336 ss.

${ }^{49}$ Ibíd., pp. 339 ss.; RenGier, R., cit. (n. 3), pp. 820 ss.

${ }^{50}$ Gómez Benítez, J. M., cit. (n. 3), pp. 341ss. 
es la estafa ${ }^{51}$. El fenómeno "presencia o ausencia de posibilidad de autoprotección" se ubica completamente fuera del significado posible de la palabra "error". Por otro lado, la invocación del principio de subsidiariedad para este delito, debería conducir a su aplicación también a otros delitos, como por ejemplo, el robo o las lesiones, con las mismas consecuencias, pues se recurre a él en tanto principio general del Derecho penal ${ }^{52}$. Se incurre en un error metodológico al adscribir la función de realización de un principio general a un concepto legal específico ${ }^{53}$. Finalmente, la invocación y aplicación del principio de subsidiariedad para determinar el error típico relevante en la estafa, puede distorsionar la función que puede cumplir este principio. En tanto principio limitador, ordena usar la sanción penal como último recurso frente a otras herramientas igualmente estatales para la protección de intereses $^{54}$. No existe una prioridad general por la autoprotección privada de la víctima antes que la intervención estatal mediante la pena ${ }^{55}$. La mentada prioridad presupone además la existencia de un deber de autoprotección de bienes por parte de la víctima, el que no tiene ningún asidero ni en un Estado de Derecho ni en la teoría política ${ }^{56}$.

Otro criterio de imputación objetiva se discute bajo el acápite de la autoexposición al peligro o autolesión de la propia víctima ${ }^{57}$. Se trata de casos en que la realización del resultado se encuentra mediada por la conducta de la propia víctima y que, tradicionalmente, se discutían en sede de autoría mediata, como un problema de autoría. Estos casos son replanteados por la teoría de la imputación objetiva ya como un problema de tipicidad objetiva ${ }^{58}$. Pues bien, aparentemente este criterio podría tener relevancia, en tanto la estafa se considere una forma especialmente tipificada de autoría mediata. Sin embargo, el fundamento de punibilidad de la autoría mediata parte de un premisa que no concurre en los delitos patrimoniales y que la diferencia estructuralmente de éstos, cual es que la realización del resultado provocada directamente por el propio autor mediato es típica y punible ${ }^{59}$. Es decir, si el autor mediato, en vez de instrumentalizar a la propia víctima, realiza él mismo

\footnotetext{
${ }^{51}$ FrISCH, Wolfgang, Funktion und Inhalt des 'Irrtums' im Betrugstatbestand, en Festschrift für Paul Bockelmann (München 1979), p. 655.

${ }^{52}$ De otra opinión, Pérez Manzano, M., cit. (n. 3), p. 223.

${ }^{53}$ Frisch, W., Comportamiento, cit. (n. 4), p. 656.

${ }^{54}$ Pawlik, Michael, Das unerlaubte Verhalten beim Betrug (Köln, 1999), p.50.

${ }^{55}$ PAWLIK, Michael, cit. (n. 54), p. 53, entre otros argumentos para rechazar el planteamiento de la victimodogmática en la estafa.

${ }^{56}$ Frisch, W., Comportamiento, cit. (n. 4), p. 160 s.

${ }^{57}$ Roxin, C., cit. (n.5), $\$ 11$ núm. 106 ss., incluye este criterio bajo el "fin de protección de la norma".

${ }^{58}$ Frisch, W., Comportamiento, cit. (n. 4), p. 171 ss.

${ }^{59}$ FrisCH, W., Funktion, cit. (n.51), p. 651.
} 
la conducta lesiva, ésta sería típica y punible. El problema que se plantea en la autoría mediata y en los casos de autoexposición al peligro o autolesión de la propia víctima, es definir los criterios en virtud de los cuales es posible imputar la realización del resultado típico al autor mediato, no obstante que es el hecho realizado por la propia víctima el que satisface descriptivamente el tipo penal. Los delitos patrimoniales parten de la premisa contraria, esto es, la provocación inmediata de un perjuicio patrimonial por el autor es en principio atípica, por la simple razón de que no existe un tipo general que castigue simplemente la defraudación a otro, la provocación de un perjuicio patrimonial a otro, como sí existe en el ámbito de los delitos contra la vida (homicidio) e incluso de los delitos contra la propiedad (daños) ${ }^{60}$. Por lo tanto, en estos delitos, los criterios de imputación de la realización del resultado a la conducta del autor, a pesar de haber sido efectuada por la propia víctima, resultan inconducentes. En consecuencia, tampoco los criterios de imputación elaborados en el grupo de casos de auto-puesta en peligro o de autolesión de la propia víctima pueden servir para la valoración de un hecho perjudicial como delito de estafa.

Por último, cabe mencionar los criterios de imputación de resultado, tradicionalmente discutidos bajo el nexo de realización entre riesgo reprobado y resultado típico. Este nexo presupone la existencia de una relación causal entre conducta y resultado ${ }^{61}$. Ya se ha puesto en cuestión el sentido de hablar de un nexo causal en la estafa, lo cual vuelve dudoso un juicio de imputación de resultado. Pues, justamente el sentido de este juicio es complementar normativamente la mera constatación de la causalidad, porque ésta se estima insuficiente para hacer responder al autor por el resultado. Podría sostenerse incluso que en los delitos patrimoniales existe sólo ese nexo de imputación sin causalidad ${ }^{62}$. Como sea, deben precisarse los criterios específicos de imputación de resultado eventualmente aplicables ${ }^{63}$. Este nexo normativo se ve excluido básicamente en dos grupos de casos. Primero, cuando el resultado típico en definitiva es realización de un riesgo distinto al jurídicamente desaprobado ${ }^{64}$. Segundo, cuando se emite un juicio hipotético, en orden a descartar ese nexo en caso que la conducta alternativa conforme a

\section{${ }^{60}$ Ibíd., p 652.}

${ }^{61}$ Cfr. Frisch, W., Comportamiento, cit. (n. 4), pp. 551 ss.

${ }^{62}$ PIÑA, J. I., cit. (n. 3) p. 49.

${ }^{63}$ Lo cual se hace de modo poco claro, por ejemplo, Pérez Manzano, M., cit. (n. 3), p. 220: "debe preguntarse, si el peligro provocado mediante el engaño ha puesto en movimiento un curso causal, que coincide con el efectivamente sucedido, y si con éste se ha realizado un resultado que la norma de cuidado infringida pretendía precisamente evitar".

${ }^{64} \mathrm{FrISCH}, \mathrm{W}$., Comportamiento, cit. (n. 4), pp. 556 ss. 
deber habría conducido inevitablemente al mismo resultado ${ }^{65}$. Estos dos juicios excluyentes del nexo de imputación son posibles en delitos de resultado como el homicidio, las lesiones e incluso daños, porque en todos ellos se trata de la provocación de un acontecimiento en el mundo de la naturaleza, que puede ser realización tanto del riesgo jurídicamente desaprobado como de otro riesgo general de la vida. El mismo acontecimiento natural, la muerte, la lesión corporal o la destrucción de la cosa, podría probablemente haberse realizado como consecuencia de una conducta alternativa hipotética conforme a deber. Pero es simplemente inimaginable el caso en que el mismo perjuicio patrimonial, la misma disminución del valor monetario del patrimonio, sea realización de un "riesgo" concurrente y distinto del engaño típico o que sea consecuencia inevitable de una conducta hipotética alternativa conforme a deber, esto es, en la estafa, no constitutiva de engaño típico.

\section{Perjuicio patrimonial: un problema de valoración, no de imputación} objetiva.

La huida metodológica hacia los criterios de imputación objetiva para dotar de contenido a los elementos típicos de los delitos patrimoniales, no parece ser muy auspiciosa. Dicho intento se estanca en la siguiente disyuntiva: o se reduce a una referencia general a la teoría de la imputación objetiva, sin precisar el modo en que sus criterios pueden operar en la configuración del injusto de estos delitos, o se aplican criterios específicos de imputación, como el riesgo permitido o el ámbito de protección de la norma, a elementos típicos para cuya interpretación se cuenta ya con una larga tradición en la dogmática de los delitos patrimoniales, con lo cual el recurso al criterio se vuelve prescindible o un gesto meramente nominal. Es lo que sucede con el elemento típico del perjuicio patrimonial, definitorio de cualquier delito patrimonial. Se trata de un elemento cuyo alcance varía según sea el concepto de patrimonio que se siga, sobre el cual dogmática y jurisprudencia vienen discutiendo desde hace más de un siglo. En cualquier caso, el perjuicio patrimonial es producto de una valoración, no es por tanto un acontecimiento que pueda imputarse según el criterio de causalidad o los distintos criterios normativos de imputación objetiva. No se puede imputar objetivamente una valoración.

Este carácter intrínsecamente valorativo del perjuicio patrimonial ha sido puesto de manifiesto, recientemente, no por la dogmática ni siquiera por la jurisprudencia de un tribunal penal. Es destacado por un fallo del Tribunal Constitucional Federal alemán, sobre la compatibilidad del tipo de administración desleal ( $\$ 266 \mathrm{StGB}$.) con el mandato de taxatividad de la Ley

${ }^{65}$ Ibíd., pp. 561 ss. 
Fundamental (artículo 103 párrafo $2^{\circ}$ ), en el que se indican los aspectos fundamentales del perjuicio patrimonial que la jurisprudencia debe considerar para mantenerse en el marco de una interpretación de la ley penal conforme a la Constitución ${ }^{66}$. Luego de mencionar el procedimiento de comparación para la determinación del perjuicio, advierte esta sentencia que debe atenderse también a la circunstancia que "el patrimonio como bien jurídico y punto de referencia de la comparación no es un objeto accesible directamente a la percepción sensorial, sino que se trata de una dimensión económica, cuyo alcance en un determinado momento resulta primeramente de una valoración. En el marco de ésta, debe decidirse qué posiciones patrimoniales se incluyen y cómo se determina su valor" ${ }^{67}$. Esta es la pregunta básica que se plantea en sede de perjuicio patrimonial, esto es, qué variables y posiciones pueden considerarse en el procedimiento de comparación y eventual compensación. Se trata, en fin, de una pregunta de valoración, no de imputación objetiva.

\section{CONCLUSIONES}

A modo de reflexión final, cabe advertir que, toda invocación a la teoría de la imputación objetiva para resolver cuestiones de parte especial del Derecho penal, debe tener presente el origen de este concepto como reformulación explícitamente normativa de la causalidad adecuada. El juicio de imputación objetiva aparece como desarrollo conceptual ulterior de la teoría de la causalidad, aspira a ser superación de ésta, pero en esa misma medida la presupone, al menos en los delitos activos de resultado. De ahí que en los delitos donde ya parece dudosa la existencia de un nexo causal, tampoco parece estar metodológicamente indicada la aplicación de criterios de imputación objetiva de resultado. Donde no existe propiamente un riesgo asociado a la realización de una conducta, no parece ser conducente un juicio de desaprobación del riesgo creado en el sentido del juicio de imputación objetiva. En los delitos patrimoniales, no existe propiamente un nexo causal ni puede hablarse en general de un riesgo asociado a la conducta típica. El juicio de imputación objetiva no juega ningún rol determinante en la imputación del perjuicio patrimonial.

${ }^{66}$ BVerfG., 2 BvR 2559/08, de 23 de julio de 2010, núm. 102 ss.

${ }^{67}$ Ibíd., núm. 103. 


\section{BiBLIOGRAFÍA}

BINDING, Karl, Eine Revolution in der Rechtsprechung des Reichsgerichts über den Betrug, en Deutsche Juristen-Zeitung (1911).

BINDING, Karl, Lehrbuch des gemeinen deutschen Strafrechts, Besonderer (2a edición, Leipzig, 1904).

FrIsCH, Wolfgang, Grundfragen der Täuschung und des Irrtums beim Betrug, en Festschrift Rolf Dietrich Herzberg (Tübingen, 2008).

FRISCH, Wolfgang, Funktion und Inhalt des 'Irrtums' im Betrugstatbestand, en Festschrift für Paul Bockelmann (München 1979).

FrIsCH, Wolfgang, Konkludentes Täuschen, en: Festschrift für Günther Jakobs (Köln, 2007).

FRISCH, Wolfgang, Comportamiento típico e imputación de resultado (Marcial Pons, Madrid, 2004).

FRISCH, Wolfgang, Faszinierendes, Berechtigtes und Problematisches der Lehre von der objektivenZurechnung des Erfolgs, en Festschrift fü Claus Roxin (2001).

GAEDE, Karsten, Die objektive Täuschungseignung als Ausprägung der objektiven Zurechnung beim Betrug, en Festschrift für Claus Roxin zum 80 Geburtstag (Berlin - New York, 2011).

Gallas, Wilhelm Der Betrug als Vermögensdelikt, en Bockelmann, Paul - Gallas, Wilhelm (editores), FestschriftfürEberhard Schmidt (Göttingen, 1961).

Gómez Benítez, José Manuel, Función y contenido del error en el tipo de estafa, en ADPCP. (1985).

Hefendehl, Roland, en Joecks - Miebach (editores), Münchener Kommentar zum Strafgesetzbuch (München, 2006), IV.

HeFENDEHL, Roland, Vermögensgefährdung und Expektanzen (Berlin, 1994).

Hernández, Héctor, Normativización del engaño y nivel de protección de la victima en la estafa: lo que dice y no dice la dogmática, en Revista Chilena de Derecho, 37 (2010) 1 .

Hillenkamp, Thomas Risikogeschäft und Untreue, en Neue Zeitschrift für Strafrecht (1981).

JaKовs, Strafrecht, Allgemeiner Teil (2a edición, Berlin - New York 1993).

JаковS, Günther,Objektive Zurechnung bei mittelbarer Täterschaft durch ein vorsatzloses Werkzeug, en Goltdammer's Archiv für Strafrecht (1997).

Kaufmann, Armin, ¿Atribución objetiva en el delito doloso? en Anuario de Derecho Penal y Ciencias Penales (1985).

KIndhäUSER, Urs, Gefährdung als Straftat (Frankfurt, 1989).

Nelles, Ursula, Untreue zum Nachteil von Gesellschaften (Berlin, Duncker \& Humblot, 1991).

Nida-Rümelin, Julian, Ethik des Risikos, en Angewandte Ethik (Stuttgart 2005).

Pawlik, Michael, Das unerlaubte Verhalten beim Betrug (Köln, 1999).

Pérez Manzano, Mercedes, Die objektive Zurechnung beim Betrug, en Schüneman

- SuÁREZ, Bausteine des europäischen Wirtschaftsstrafrechts. Symposium für Klaus Tiedemann (Köln, 1994).

Piña, Juan Ignacio, Fraude de seguros (Santiago, Editorial Jurídica, 2006).

Puppe, Ingeborg, Die Erfolgszurechnung im Strafrecht (Baden-Baden, 2000).

RENGIER, Rudolf, Gedanken zur Problematik der objektiven Zurechnung im Besonderen Teil des Strafrechts, en Festschrift für Claus Roxin (Berlin - New York, 2001). 
Riemann, Thomas, Vermögensgefährdung und Vermögensschaden (Heidelberg, 1989).

Rojas, Luis Emilio, Grundprobleme der Haushaltsuntreue. Zugleich ein Beitrag zur Dogmatik der Untreue, en StGB. 266 (Baden-Baden 2011).

Rojas, Luis Emilio, Lo subjetivo en el juicio de imputación objetiva ¿aporía teórica? en Revista de Derecho, 23 (Valdivia, 2010) 1.

Roxin,Claus, Strafrecht (4a edición, München, 2006).

SALIGER, Frank, Rechtsprobleme des Untreuetatbestandes, en Juristische Arbeitsblätter (2007).

Laufhütt - Rissing - van SAa - Tiedemann (editores), Strafgesetzbuch Leipziger Kommentar (11 a edición, Berlin, 1999), IX. 